\author{
Marquette University \\ e-Publications@Marquette
}

$7-2005$

\title{
Memory Enhancement by a Semantically Unrelated Emotional Arousal Source Induced After Learning
}

Kristy A. Nielson

Marquette University, kristy.nielson@marquette.edu

Douglas Yee

Marquette University

Kirk I. Erickson

Marquette University

Follow this and additional works at: https://epublications.marquette.edu/psych_fac

Part of the Psychology Commons

\section{Recommended Citation}

Nielson, Kristy A.; Yee, Douglas; and Erickson, Kirk I., "Memory Enhancement by a Semantically Unrelated Emotional Arousal Source Induced After Learning" (2005). Psychology Faculty Research and Publications. 108.

https://epublications.marquette.edu/psych_fac/108 


\title{
Memory enhancement by a semantically unrelated emotional arousal source induced after learning
}

\author{
Kristy A. Nielson \\ Department of Psychology, Marquette University, \\ Milwaukee, WI \\ Integrative Neuroscience Research Center, Marquette University, \\ Milwaukee, WI \\ Foley Center for Aging and Development, \\ Department of Psychiatry and Behavioral Medicine, \\ Medical College of Wisconsin \\ Douglas Yee \\ Department of Psychology, Marquette University, \\ Milwaukee, WI \\ Kirk I. Erickson \\ Department of Psychology, Marquette University, \\ Milwaukee, WI
}

\begin{abstract}
It has been well established that moderate physiological or emotional arousal modulates memory. However, there is some controversy about whether the


source of arousal must be semantically related to the information to be remembered. To test this idea, 35 healthy young adult participants learned a list of common nouns and afterward viewed a semantically unrelated, neutral or emotionally arousing videotape. The tape was shown after learning to prevent arousal effects on encoding or attention, instead influencing memory consolidation. Heart rate increase was significantly greater in the arousal group, and negative affect was significantly less reported in the non-arousal group after the video. The arousal group remembered significantly more words than the non-arousal group at both $30 \mathrm{~min}$ and $24 \mathrm{~h}$ delays, despite comparable group memory performance prior to the arousal manipulation. These results demonstrate that emotional arousal, even from an unrelated source, is capable of modulating memory consolidation. Potential reasons for contradictory findings in some previous studies, such as the timing of "delayed" memory tests, are discussed.

Keywords: Memory consolidation, Heart rate, Galvanic skin response, Electrodermal activity, Skin conductance, Long-term memory, Emotion, Memory modulation, Arousal

\section{I ntroduction}

It has long been known that some events or facts are remembered better than are others and that emotionally arousing events are recollected with greater frequency than similar but emotionally neutral events. From a number of perspectives enhanced memory for emotional events is adaptive, effectively making important stimuli stand apart from those that are less significant (McGaugh, 1990), and thus protecting and preparing an organism for similar occasions in the future. Many psychological studies have investigated factors that might explain the memory advantage for emotional events, such as enhanced attention and elaboration (e.g., Revelle \& Loftus, 1992; Walker, 1958). Although these factors play a role in the memory advantage of emotionally charged information, they are likely insufficient to explain it (e.g., Bohannon, 1988; Conway et al., 1994; Guy \& Cahill, 1999). Less often discussed are the neural and endogenous hormonal mechanisms that are preferentially engaged in response to arousing or emotive stimuli that can enhance memory (cf. Gold \& McGaugh, 1975; McGaugh, 1990, 2000).

Memory consolidation, the means of storing a memory, is the outcome of a complex set of neurobiological processes occurring over a period of time (cf. Deutsch \& Deutsch, 1966; McGaugh, 2000; Müller \& Pilzecker, 1900; Torras-Garcia, Portell-Cortes, Costa-Miserachs, \&

Neurobiology of Learning and Memory Vol 84, No. 1 (July 2005): pg. 49-56. DOI. This article is (C) Elsevier and permission has been granted for this version to appear in e-Publications@Marquette. Elsevier does not grant permission for this article to be further copied/distributed or hosted elsewhere without the express permission from Elsevier. 
Morgado-Bernal, 1997). As such, events occurring during, or even shortly after learning can alter, or modulate, the consolidation of memory. Although emotional events naturally involve arousal onset during the event itself, it typically persists also for some time afterward. Therefore, like other arousal sources, emotion can have physiological effects on memory consolidation, rather than just on encoding and attention. Indeed, although arousal can facilitate detection and encoding for long-term retention, it can also hinder retrieval for as much as 30 min (Revelle \& Loftus, 1992; Walker, 1958).

A variety of substances, including glucose and the adrenal hormones epinephrine, norepinephrine, and cortisol are released into the bloodstream during times of arousal, stress and emotion (Gold \& McCarty, 1981) and have been closely linked to memory enhancement (e.g., Czech, Nielson, \& Laubmeier, 2000; McGaugh, 2000; Nielson, Czech, \& Laubmeier, 1999; Nielson \& Jensen, 1994; van Stegeren, Everaerd, Cahill, McGaugh, \& Gooren, 1998). Many animal studies have consistently shown that these substances alter memory and that they generally follow the classic inverted- $U$ dose-response effect (Yerkes \& Dodson, 1908) on memory performance (McGaugh, 1990, 2000). These effects are also time-dependent, such that doses administered during or shortly after learning are effective, but those administered $30 \mathrm{~min}$ or $2 \mathrm{~h}$ after learning are ineffective (Gold \& van Buskirk, 1975; but see also Powless et al., 2003).

Most of the research on the processes of memory modulation has been done in animal models. The animal research demonstrating a locus of the effect of memory modulators on the consolidation process is important for evaluating the results of human studies, which have instead primarily manipulated arousal during encoding. In seeming conflict to what would be expected based on the findings in the animal literature, a number of authors of human studies have concluded that arousal only affects memory if it is semantically related to the material being remembered, purportedly because high attentional selectivity induced by arousal is assumed to interfere with memory (i.e., Easterbrook, 1959). For example, Christianson and Mjörndal (1985) found that epinephrine injections, an unrelated arousal source, produced physiological and subjective arousal but did not enhance memory performance for faces over saline injections. Christianson, 
Nilsson, Mjörndal, Perris, and Tjelldén (1984) also found that saline injected participants shown traumatic pictures remembered significantly less than epinephrine injected participants shown neutral materials (i.e., unrelated arousal source). Buchanan and Lovallo (2001) found that pre-learning injections of cortisol selectively enhanced delayed memory for arousing pictures but not neutral pictures. Varner and Ellis (1998) did two experiments manipulating mood and arousal state either before or after learning. They found mood- and theme-congruence effects, but physiological arousal via exercise did not affect word retrieval. Finally, Libkuman, NicholsWhitehead, Griffith, and Thomas (1999) examined source of arousal on memory for details in a series of experiments finding that emotional arousal enhanced memory but physiological arousal by exercise had no effect. They concluded “....in order for arousal to have any impact on memory, it must be relevant to the to-be-remembered event; merely arousing someone will not suffice (p. 180)."

At best the relationship amongst emotion or arousal and memory is as yet incompletely understood. Although the human studies described have significantly contributed to our understanding of the effects of emotion on memory, each also had significant limitations precluding strong conclusions about the role of arousal per se in memory. In some studies, the degree of arousal achieved in the experiment was potentially too high to enhance memory (e.g., Christianson et al., 1984), and in some studies, memory for different materials was compared across groups (e.g., Christianson et al., 1984; Libkuman et al., 1999), or sources of arousal were combined from external and stimulus sources, which clouds the issue of the effect of arousal source on memory. Importantly, in most of these studies, arousal was manipulated during the encoding phase of the tasks employed, which confounded the effects of arousal on attention and encoding with its effects on consolidation (Buchanan \& Lovallo, 2001; Christianson \& Mjörndal, 1985; Christianson et al., 1984; Libkuman et al., 1999). Finally, previous animal and human research makes clear that memory consolidation takes time (e.g., McGaugh, 2000; Revelle \& Loftus, 1992; Walker, 1958), but each of these previous studies used very short-term retention tests (10-15 min delay), potentially missing the effects of the arousal manipulation (Buchanan \& Lovallo, 2001; Christianson \& Mjörndal, 1985; Christianson et al., 1984; Libkuman et al., 1999; Varner \& Ellis, 1998). Indeed, a recent study showed that 
an emotional version of a story produced better 1-week delayed retrieval of the story than did a neutral version, but there was no difference in retrieval when only a short $1 \mathrm{~h}$ delay was used (Quevedo et al., 2003).

Studies specifically examining the effects of arousal on the memory consolidation process in humans are limited. Nicotine (Colrain, Mangan, Pellett, \& Bates, 1992), glucose (Manning, Parsons, $\&$ Gold, 1992), and muscle tension (Nielson \& Jensen, 1994; Nielson, Radtke, \& Jensen, 1996) have been shown to enhance delayed retrieval of non-arousing memory materials when given after learning. For example, Nielson and Jensen (1994) showed that induction of muscle tension shortly after exposure to target words embedded in paragraphs increased heart rate and enhanced delayed recall and recognition of the words, except in participants who were taking $\beta$ blockers to control hypertension. Importantly, immediate retrieval was not affected by arousal. Similarly, a list-learning study showed that hypermnesia, improvement in memory over time, was inhibited by showing a violent videotape (high arousal), only when shown after initial list-learning compared with presentation before learning or with use of a neutral stimulus (Shaw, Bekerian, \& McCubbin, 1995).

One potential limitation of the studies by Nielson and colleagues (Nielson \& Jensen, 1994; Nielson et al., 1996) is that the arousal source used was physiological, but designed to be relatively nonemotive (i.e., muscle tension). As such, it could be argued that an emotional arousal source could produce different effects. Therefore, the present study was designed to determine if moderate emotional arousal from a source semantically unrelated to the to-be-remembered material, induced after learning, would enhance delayed memory performance. It was hypothesized that exposure to an emotionally arousing stimulus after learning a list of words would produce acute physiological arousal. In addition, the arousal stimulus was expected to enhance delayed retention performance (30 $\mathrm{min}$ and $24 \mathrm{~h}$ ) for the word list.

\section{Method}

\subsection{Participants}

Neurobiology of Learning and Memory Vol 84, No. 1 (July 2005): pg. 49-56. DOI. This article is @ Elsevier and permission has been granted for this version to appear in e-Publications@Marquette. Elsevier does not grant permission for this article to be further copied/distributed or hosted elsewhere without the express permission from Elsevier. 
Thirty-five undergraduate students ( 13 male, 22 female) aged 18-23 years were included in this study and some received course credit for their participation. All subjects were randomly assigned to the arousal or non-arousal condition and tested individually with procedures approved by the Institutional Review Board.

\subsection{Materials and apparatus}

Thirty high-imagery nouns were selected to equilibrate memorability ( $>6.0$ on a scale of 1-7, Paivio, Yuille, \& Madigan, 1968, e.g., "butterfly," "queen," "house") and recorded onto a videotape using white letters on a dark blue background and presented at $3 \mathrm{~s}$ intervals with no interstimulus interval as an intentional memory test. None of the words selected were from dental, oral, medical, or tool categories. Of the 30, 19 have also been standardized for subjective arousal response (Bradley $\&$ Lang, 1999), showing they fall in the lowmoderate range with little variability $(M=4.65, S D=0.81$; range $=3.17-6.27$ on a 9-point scale); imageable nouns are not typically found in the lower ratings range (cf. Bradley \& Lang, 1999).

The arousal condition was manipulated using videotaped liveaction demonstrations ( $3 \mathrm{~min}$ ) of either oral surgery (arousal) or tooth-brushing (non-arousal). Immediate, $30 \mathrm{~min}$ and $24 \mathrm{~h}$ delayed recall tests and a $24 \mathrm{~h}$ recognition test were used to assess memory for the word list. Participants were given up to $3 \mathrm{~min}$ to recall, in writing, as many of the words from the list as possible. The recognition test consisted of 140 words (the 30 list items and 110 distracter words, using the same criteria used for the target list), presented in five columns of 28 words each. Participants were instructed to mark all words that they believed were from the original word list.

Several questionnaires were administered, including the Wechsler Adult Intelligence Scale-Revised Vocabulary Subtest (WAISRV) (Wechsler, 1981), the 14-item Perceived Stress Scale (PSS, Cohen, Kamarck, \& Mermelstein, 1983), the 21-item Beck Depression Inventory (BDI, Beck, Ward, Mendelson, Mock, \& Erbaugh, 1968), the 21-item Beck Anxiety Inventory (BAI, Beck, Brown, Epstein, \& Steer, 1988), and a 14-item negative affect adjective rating scale designed to measure current affective state based on the Emotional Intensity Scale (EIS, Bachorowski \& Braaten, 1994). Items included sad, sick, angry,

Neurobiology of Learning and Memory Vol 84, No. 1 (July 2005): pg. 49-56. DOI. This article is (C) Elsevier and permission has been granted for this version to appear in e-Publications@Marquette. Elsevier does not grant permission for this article to be further copied/distributed or hosted elsewhere without the express permission from Elsevier. 
surprised, disgust, etc. Only negative adjectives were used due to the negative orientation of the arousal stimulus.

Heart rate and galvanic skin response (skin conductance) were measured continuously throughout the first session. Heart rate (beats per minute) was measured using a photoplethysmograph placed on the thumb pad of the non-dominant hand, and galvanic skin response (micro mho) was measured using electrodes on the 2 nd and 3 rd fingers of the same hand. These data were collected at a rate of $16 \mathrm{~Hz}$ using Virtual Instruments MasterLab (Expanded Technologies, Shreveport, LA).

\subsection{Procedure}

After a brief study explanation was given and informed consent was obtained, the electrodes were placed on the non-dominant hand (fingers 2, 3; photoplethysmograph on the thumb). The word list was then presented via videotape with instruction to repeat the words aloud as they were presented and to intentionally try to remember them. Immediate recall performance was then tested. A 5 min rest period, without activity was then given to establish baseline heart rate and galvanic skin response; minutes 2-5 constituted the computed baseline. The EIS was then administered, followed by the arousal manipulation, given by videotape with the instruction to watch it carefully and in its entirety. Physiological measures were recorded until 5 min had elapsed, including the 3 min video period and the $2 \mathrm{~min}$ directly following it. A second EIS assessment were then made, followed by administration of the PSS, BDI, and BAI, as well as a variety of other personality measures used as filler. After $30 \mathrm{~min}$ had elapsed, an unannounced delayed recall test was given. When participants returned $24 \mathrm{~h}$ later, expecting a session similar to the first, unannounced delayed recall and recognition tests were given, followed by the WAISR-V.

Statistical analyses. Recognition scores were corrected for guessing using: corrected recognition $=(1-E R) *(\%$ Hits $)$, where $\%$ Hits $=$ Hits $/ 30$ Targets and Error Rate $(E R)=$ proportion of false alarms (FA/110 Distracters). The physiological data were reduced to one measure per $5 \mathrm{~s}$ interval for each index. Three indices were then computed by averaging the $5 \mathrm{~s}$ intervals over the measurement

Neurobiology of Learning and Memory Vol 84, No. 1 (July 2005): pg. 49-56. DOI. This article is (C) Elsevier and permission has been granted for this version to appear in e-Publications@Marquette. Elsevier does not grant permission for this article to be further copied/distributed or hosted elsewhere without the express permission from Elsevier. 
epoch: 3 min baseline epoch, 3 min stimulus epoch (i.e., videotape viewing), and 2 min post-stimulus epoch. Difference or change scores, subtracting stimulus and post-stimulus periods from baseline, as well as post-arousal EIS to baseline EIS, were computed and compared between groups using one-way analysis of variance (ANOVA). Analysis of covariance (ANCOVA) was used to control for possible nonexperimental group differences in the memory analyses. Additional comparisons were made by t test, as indicated. All analyses were performed using Statistical Package for the Social Science (SPSS, Chicago, IL), ver. 11.0 for Windows.

\section{Results}

\subsection{Demographics}

Characteristics of subjects in the arousal and non-arousal groups are provided in Table 1 . Comparison by t test indicated that no statistically significant differences $(p>.05)$ were observed between the groups for WAIS-R Vocabulary, PSS, BDI, or BAI.

Table 1. Group demographic data (mean \pm SEM)

\begin{tabular}{llllll}
\multicolumn{1}{c}{ Group } & \multicolumn{1}{c}{ Gender } & \multicolumn{1}{c}{ WAI S-R Vocabulary } & \multicolumn{1}{c}{ PSS } & \multicolumn{1}{c}{ BDI } & \multicolumn{1}{c}{ BAI } \\
Arousal & 6 Male & 48.5 & 45.9 & 6.8 & 6.4 \\
& 10 Female & $(2.5)$ & $(0.97)$ & $(1.6)$ & $(1.46)$ \\
Non-arousal & 7 Male & 48.4 & 48.2 & 6.2 & 7.6 \\
& 12 Female & $(1.7)$ & $(1.1)$ & $(1.4)$ & $(0.82)$ \\
$\mathrm{t}(33)=$ & & .03 & -1.5 & .31 & -.66
\end{tabular}

All independent samples $t$ tests were non-significant $(p>.05)$. WAIS-R, Wechsler Adult Intelligence Scale-Revised; PSS, Perceived Stress Scale; BDI, Beck Depression Inventory; BAI, Beck Anxiety Inventory.

\subsection{Memory performance}

An immediate recall test was given, after list-learning but prior to the arousal manipulation, to verify that participants paid attention to the task and that the groups had generally comparable memory ability. The groups did not significantly differ (arousal group: $M=41.2 \%, S D=11.9$; non-arousal group: $M=36.5 \%, S D=8.9$; $F(1,33)=1.8, p=.19)$. However, immediate recall performance was 
used as a covariate in the delayed memory analyses to remove any effects of the initial performance differences among participants.

Fig. 1 shows the mean percentage of words recalled and recognized at each of the delayed retention tests by participants in both arousal conditions. A 2 (Group; between) × 3 (Memory Tests; within) repeated measures ANCOVA (immediate recall $=$ covariate) revealed a significant effect for Memory Tests $(F(2,64)=21.3$, $p=.001)$, which can be attributed to the difference in performance level of recall vs. recognition, as expected. There was also a significant effect of Group $(F(1,32)=9.2, p=.005)$, such that the arousal group outperformed the non-arousal group overall (see Fig. 1). There was no significant interaction effect $(F(1,32)=2.0, p=.14)$. As a follow-up, a 2 Group $\times 2$ Memory Tests ( $30 \mathrm{~min}$ and $24 \mathrm{~h}$ recall) ANCOVA showed a marginal effect of Memory Tests $(F(1,32)=3.72$, $p=.06)$, a significant Group difference (Group $F(1,32)=3.9$, $p=.05)$, and a non-significant Interaction $(F(1,32)=0.11, p=.74)$. Confirmatory one-way ANOVAs showed significantly better performance by the arousal group for each retention test: 30 min delayed recall $(F(1,33)=5.0, p=.03), 24 \mathrm{~h}$ delayed recall $(F(1,33)=4.8, p=.04)$, and $24 \mathrm{~h}$ recognition $(F(1,33)=10.6$, $\mathrm{p}=.003)$.

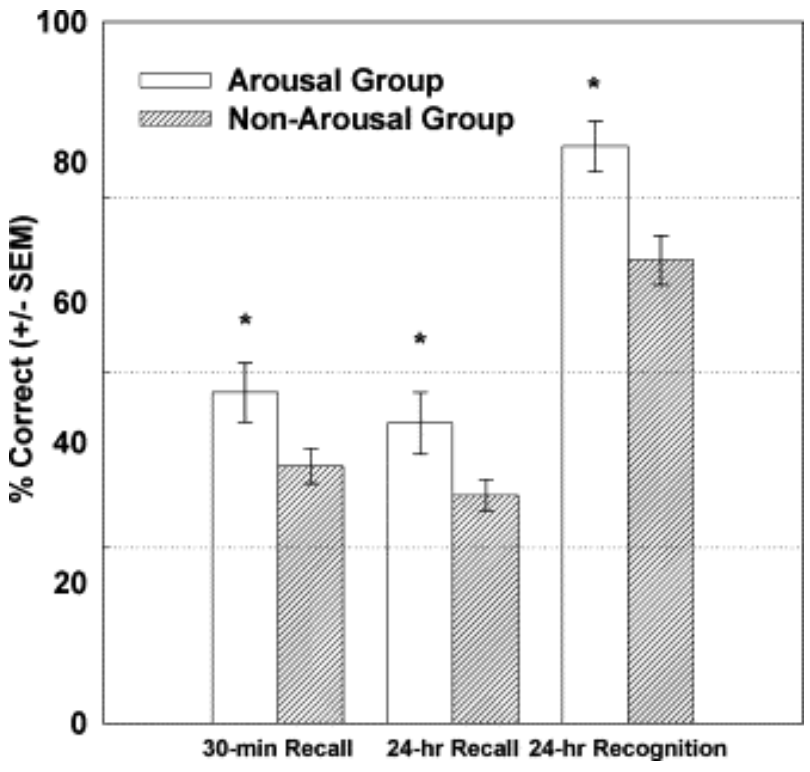

Fig. 1. The mean percentages of words recalled and recognized by participants in the arousal and non-arousal groups are presented for each index. Immediate recall, which 
NOT THE PUBLISHED VERSION; this is the author's final, peer-reviewed manuscript. The published version may be accessed by following the link in the citation at the bottom of the page.

occurred prior to the arousal manipulation and did not differ significantly between the groups $(p>.05)$, was used to control for covariance in the analysis of the remaining memory tests. The arousal group outperformed the non-arousal group at each delayed retention test $(* ; p<.05)$.

\subsection{Arousal response measures}

Baseline measures were within normal ranges and not significantly different between groups for either heart rate (HR; arousal mean $=72.2, \mathrm{SD}=2.6$; non-arousal mean $=72.8, \mathrm{SD}=2.9$; $F(1,33)=.02, p=.90)$ or galvanic skin response (GSR; arousal mean $=11.6, \mathrm{SD}=1.3$; non-arousal mean $=10.8, \mathrm{SD}=1.2$; $F(1,33)=.19, p=.70)$. Because change from baseline is the common form of analysis for these types of data to control for variability in absolute scores within and between groups (and was planned for this reason), a one-way ANOVA comparing the HR difference or change scores (tape-baseline, post-tape-baseline) between groups showed that the arousal group had significantly higher heart rate than the non-arousal group during the stimulus $(F(1,33)=5.2, p=.03)$ and post-stimulus intervals $(F(1,33)=5.6$, $p=.02$ ). The comparison of change scores (tape-baseline, posttape-baseline) between groups for GSR showed no difference between the groups (tape: $F(1,33)=0.5, p=.83$; post-tape: $F(1,33)=.19, p=.66)$. Subjective response to the arousal manipulation, measured using the self-report adjective rating scale, were compared using a difference score analysis between post- and pre-video sums. One-way ANOVA showed a significant difference between the groups $(F(1,33)=9.7, p=.004)$, where the non-arousal group had lower negative affective ratings than the arousal group. These results are shown in Fig. 2. 
NOT THE PUBLISHED VERSION; this is the author's final, peer-reviewed manuscript. The published version may be accessed by following the link in the citation at the bottom of the page.

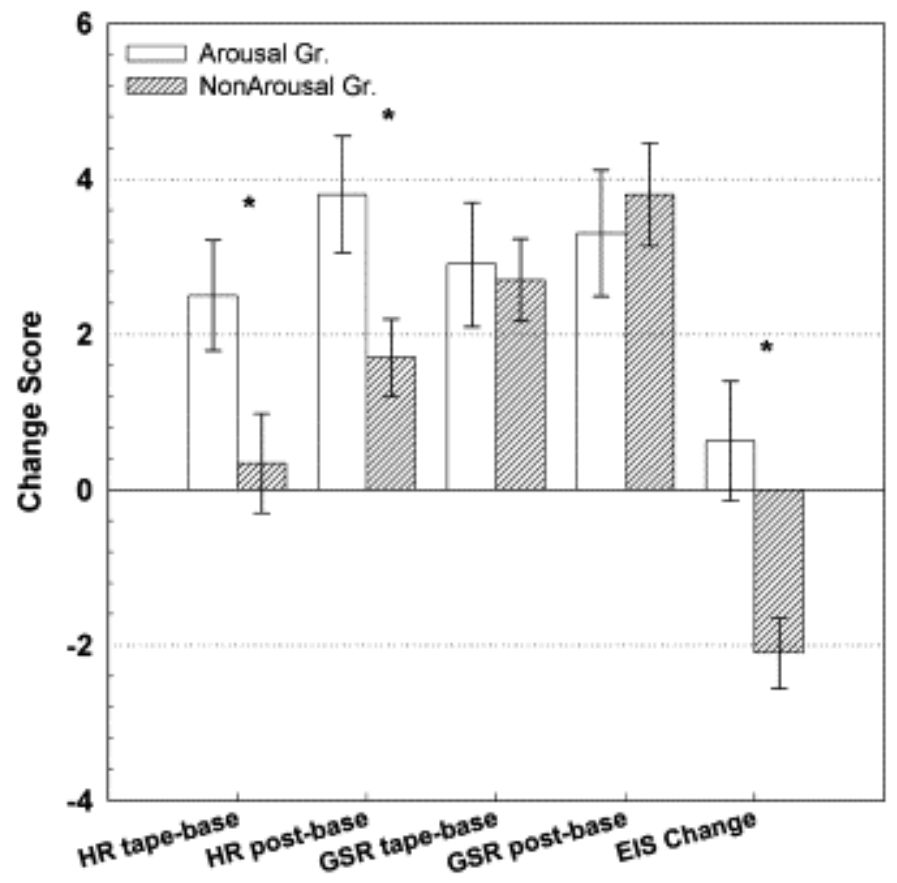

Fig. 2. Shown separately for the arousal and non-arousal groups is change from baseline in heart rate (HR; beats per minute) and galvanic skin response (GSR; micromho), during both the video stimulus (tape) and post-video intervals (post). Heart rate significantly increased in the arousal group relative to the non-arousal group (*; $\mathrm{p}<.05$ ). Subjective arousal change scores (pre to post video) are also shown (emotional intensity scores; EIS; negative adjective sum). The arousal group reported more negative feelings while the non-arousal group reported less negative feelings after their respective videos $(* ; p<.05)$.

\section{Discussion}

The purpose of the present study was to investigate the ability of emotional arousal induced after learning to affect memory consolidation, and whether it is necessary for the source of arousal to be semantically associated with the learned material for modulation to occur. The results of this study support the hypothesis that emotionally induced arousal enhances delayed memory performance. Significantly better recall and recognition scores were obtained for the arousal group than for the non-arousal group on the 30 min test and on both $24 \mathrm{~h}$ delayed retention tests. The difference averaged more than $8 \%$ for recall (approximately 2.5 items), and $13 \%$ for recognition (approximately 3.9 items). Although galvanic skin response did not show a significant effect of arousal, moderate physiological arousal was documented by a significant increase in heart rate. Therefore, the

Neurobiology of Learning and Memory Vol 84, No. 1 (July 2005): pg. 49-56. DOI. This article is (C) Elsevier and permission has been granted for this version to appear in e-Publications@Marquette. Elsevier does not grant permission for this article to be further copied/distributed or hosted elsewhere without the express permission from Elsevier. 
present findings are consistent with those of previous studies in both the animal and human literatures demonstrating that memories are consolidated over time and that the events occurring shortly after learning can modulate memory (McGaugh, 2000; Nielson \& J ensen, 1994; Nielson et al., 1996; Shaw et al., 1995).

In the present study, memory was significantly enhanced in the arousal group by a semantically unrelated emotional stimulus. These results contrast with other studies whose authors concluded that the arousal source must be related to the to-be-remembered material (e.g., Christianson \& Mjörndal, 1985; Christianson, Nilsson, Mjörndal, Perris, \& Tjelldén, 1986; Libkuman et al., 1999). Importantly, the memory stimuli were both temporally and semantically distinct from the source of arousal. The contradictory findings could be due to the isolation of the effect in the present study to the memory consolidation interval, which prevented confounding with encoding or attention effects, or material differences across conditions. In addition or alternatively, the contrasting findings could be due to the use of shortterm retention tests in past studies, which is not ideal to measure retention because arousal inhibits retrieval in the short-term (e.g., Nielson \& Jensen, 1994; Nielson et al., 1996; Revelle \& Loftus, 1992) and consolidation effects appear later in time (McGaugh, 2000; Revelle \& Loftus, 1992; Torras-Garcia et al., 1997; Walker, 1958). Indeed, Quevedo et al. (2003) demonstrated that an emotional version of a story produced better long-term ( 1 week) retrieval but not short-term ( $1 \mathrm{~h}$ ) than did a matched neutral version. The authors concluded that the amygdala plays a role in long-term but not short-term memory mechanisms. An alternative interpretation is that the effects of arousal, via the amygdala, had not yet consolidated enough to show the effect. These results are consistent with the current study.

A variety of substances, including glucose and the adrenal stress hormones epinephrine and cortisol are released into the bloodstream during times of arousal; stress and emotion and have been closely linked to memory consolidation via peripheral or central receptors and brain stem actions (e.g., nucleus of the solitary tract) (cf. McGaugh, 2000). These in turn affect amygdala activation via norepinephrine, and its basolateral $\beta$-adrenergic receptors play a central role in both adrenergic and glucocorticoid effects on memory by modulating hippocampal and striatal activity (cf. McGaugh, 2000). The current

Neurobiology of Learning and Memory Vol 84, No. 1 (July 2005): pg. 49-56. DOI. This article is @ Elsevier and permission has been granted for this version to appear in e-Publications@Marquette. Elsevier does not grant permission for this article to be further copied/distributed or hosted elsewhere without the express permission from Elsevier. 
study indirectly supports this biological model. The learned material was not inherently arousing, but an arousing stimulus presented after learning enhanced later retrieval. The arousal response was validated by both subjective response and heart rate, suggesting an adrenal hormone response. Very compatible heart rate and memory modulation results were reported in a previous study that also verified that the mechanism of action of the effect involves $\beta$-adrenergic receptors (Nielson \& J ensen, 1994).

The present findings suggest that arousal induced after learning could potentially enhance retention for any type of material. Livingston (1967) proposed such an idea, that hormone response to stress that occurs after learning can modulate memory for any recently acquired information. Our findings are consistent with this proposition, as were a number of other studies using an arousing treatment after learning of non-emotive stimuli (Colrain et al., 1992; Manning et al., 1992; Nielson \& J ensen, 1994; Nielson et al., 1996). However, the present findings contrast with a recent few recent studies that suggest that post-learning arousal may only be effective to modulate inherently arousing stimuli (Cahill, Gorski, \& Le, 2003) or that some amount of arousal or novelty at encoding is necessary for post-learning arousal treatments to modulate memory (Cahill \& Alkire, 2003; Okuda, Roozendaal, \& McGaugh, 2004). The present study cannot directly address these issues because arousal was not measured during encoding. However, because post-training arousal enhanced overall retention for a 30-item word list, it is unlikely that situational arousal at the beginning of the session was responsible. Alternatively, novelty of the task and situation could have interacted with arousal induced after learning. Yet, college students frequently experience very similar learning situations and tasks and do not have elevated subjective or physiological baseline arousal, prior to task commencement, relative to later in the session (Nielson \& J ensen, 1994; Stone \& Nielson, 2001). Moreover, memory modulation systems might preferentially affect memory for arousing information when such information occurs, but be less preferential when information is more neutral. Furthermore, both epinephrine and norepinephrine given after learning can enhance memory for emotional materials (Cahill \& Alkire, 2003; Southwick et al., 2002), but epinephrine's effects may be only for emotional materials (Cahill \& Alkire, 2003), suggesting that the two mechanisms may have differential roles depending on task or stimulus conditions. 
Cortisol release associated with the arousal could also be responsible for the current effects. Although several studies have shown that cortisol given before learning or just before retrieval impairs memory retrieval, cortisol levels likely remained elevated at retrieval during these studies (de Quervain et al., 2003; de Quervain, Roozendaal, Nitsch, McGaugh, \& Hock, 2000; Kuhlmann, Kirschbaum, $\&$ Wolf, 2005; Wolf et al., 2001). When given shortly after learning and when levels return to baseline prior to testing, a number of studies show that glucocorticoids alter memory consolidation in an inverted- $U$ fashion, similar to epinephrine (Abercrombie, Kalin, Thurow, Rosenkranz, \& Davidson, 2003; de Quervain et al., 2000). Indeed recent research suggests that adrenergic and glucocorticoid hormones may interact (Maheu, Joober, Beaulieu, \& Lupien, 2004), indicating that further studies are needed to evaluate their specific roles in arousal and memory modulation studies.

The arousal stimulus induced heart rate changes but not GSR changes. Heart rate has complex physiological control, innervated by both the sympathetic and parasympathetic nervous systems. The Intake-Rejection hypothesis (Lacey \& Lacey, 1970) states that stimulus intake (externally oriented processing) typically causes heartrate deceleration, while stimulus rejection (internally oriented processing) typically causes heart-rate acceleration. Indeed, when stimuli vary on valence, and particularly when they are unpleasant, deceleration often occurs (Gomez, Zimmermann, \& Guttormsen-Schar, 2005; Kemp \& Nathan, 2004), while stimuli associated more with stronger arousal responses, fear, imagery or social induction tasks often show acceleration (Ekman, Levenson, \& Friesen, 1983; Witvliet \& Vrana, 1995). Based on this literature, heart rate deceleration might have been expected in the current study. However, the 3 min video of live-action oral surgery produced significant heart rate acceleration. It was negatively valenced, but also with uncomfortable sights of blood and sounds of drilling and suctioning. Dental procedures have strong negative imagery and often provoke fear reactions. Furthermore, heart rate was significantly elevated by this same stimulus in another study (Stone \& Nielson, 2001). Thus, this stimulus likely produces rejection processing. Nevertheless, emotional or arousing stimuli of both positive and negative valence produce adrenal activity and stress hormone release, which can influence memory consolidation (e.g., McGaugh, 2000; Nielson \& Bryant, 2005; Nielson \& Jensen, 1994; van 
Stegeren et al., 1998). It remains to be evaluated whether heart rate acceleration or deceleration associated with emotional or arousing stimuli produce differential effects on memory consolidation.

Several recent studies have indicated gender differences in the processing of emotional memories (Cahill et al., 2001; Canli, Desmond, Zhao, \& Gabrieli, 2002) and responsiveness to memory modulation techniques (Cahill \& van Stegeren, 2003). Indeed, one recent study found gender-role identity differences, rather than actual gender differences in emotional memory scores (Cahill, Gorski, Belcher, \& Huynh, 2004). The present study was not designed to evaluate gender differences, having a nearly 2:1 ratio of females to males, which would yield small cell sizes if further analyzed by gender. The ever-increasing ratio of female to male students in psychology programs, who constitute the participants for many such studies, frequently results in this discrepancy. Although this is difficult to address, gender and gender-related effects should be more specifically evaluated in future studies.

In summary, participants who viewed an emotionally arousing videotape after learning a list of words exhibited a significantly greater acute arousal response and significantly better delayed memory performance ( $30 \mathrm{~min}$ and $24 \mathrm{~h}$ ) than subjects who viewed a nonarousing tape after learning. These findings are consistent with both animal and human studies, demonstrating that emotion and arousal affect the consolidation of memory after the learning event and, contrary to some reports, that the source of arousal need not be associated with the material to be remembered. These findings further suggest that such a technique could be applied as a memory intervention strategy and that it could be effective for a wide variety of learning situations.

\section{Acknowledgments}

The authors wish to gratefully acknowledge the Marquette University School of Dentistry for video stimuli and the assistance of Linda Stone with data collection. This research was supported, in part, by a Summer Faculty Fellowship to K. Nielson by the Graduate School of Marquette University, and by a Summer Opportunities for Academic Research Scholarship to D. Yee from the Ronald E. McNair Scholars Program.

Neurobiology of Learning and Memory Vol 84, No. 1 (July 2005): pg. 49-56. DOI. This article is @ Elsevier and permission has been granted for this version to appear in e-Publications@Marquette. Elsevier does not grant permission for this article to be further copied/distributed or hosted elsewhere without the express permission from Elsevier. 
NOT THE PUBLISHED VERSION; this is the author's final, peer-reviewed manuscript. The published version may be accessed by following the link in the citation at the bottom of the page.

\section{References}

Abercrombie et al., 2003

H.C. Abercrombie, N.H. Kalin, M.E. Thurow, M.A. Rosenkranz, R.J. Davidson. Cortisol variation in humans affects memory for emotionally laden and neutral information. Behavioral

Neuroscience, 117 (2003), pp. 505-516

Bachorowski and Braaten, 1994

J. Bachorowski, E.B. Braaten. Emotional intensity: Measurement and theoretical implications. Personality and Individual

Differences, 17 (1994), pp. 191-199

Beck et al., 1988

A.T. Beck, G. Brown, N. Epstein, R.A. Steer. An inventory for measuring clinical anxiety: psychometric properties. J ournal of Consulting and Clinical Psychology, 56 (1988), pp. 893-897

Beck et al., 1968

A.T. Beck, C.H. Ward, M. Mendelson, J. Mock, J. Erbaugh. An inventory for measuring depression. Archives of General

Psychiatry, 4 (1968), pp. 53-63

Bohannon, 1988

N.J . Bohannon. Flashbulb memories for the space shuttle disaster: A tale of two theoriesCognition, 29 (1988), pp. 179196

Bradley and Lang, 1999

Bradley, M. M., \& Lang, P. J. (1999). Affective norms for English words (ANEW): Instruction manual and affective ratings (Technical Report C-1). Gainsville, FL: The Center for Research in Psychophysiology, University of Florida

Buchanan and Lovallo, 2001

T.W. Buchanan, W.R. Lovallo. Enhanced memory for emotional material following stress-level cortisol treatment in humans.

Psychoneuroendocrinology, 26 (2001), pp. 307-317

Cahill and Alkire, 2003

L. Cahill, M.T. Alkire. Epinephrine enhancement of human memory consolidation: Interaction with arousal at encoding. Neurobiology of Learning and Memory, 79 (2) (2003), pp. 194198

Cahill et al., 2004

Neurobiology of Learning and Memory Vol 84, No. 1 (July 2005): pg. 49-56. DOI. This article is (C) Elsevier and permission has been granted for this version to appear in e-Publications@Marquette. Elsevier does not grant permission for this article to be further copied/distributed or hosted elsewhere without the express permission from Elsevier. 
L. Cahill, L. Gorski, A. Belcher, Q. Huynh. The influence of sex versus sex-related traits on long-term memory for gist and detail from an emotional story. Consciousness and Cognition, 13 (2004), pp. 391-400

Cahill et al., 2003

L. Cahill, L. Gorski, K. Le. Enhanced human memory consolidation with post-learning stress: Interaction with the degree of arousal at encoding. Learning and Memory, 10 (4) (2003), pp. 270-274

Cahill et al., 2001

L. Cahill, R. Haier, N.S. White, J. Fallon, L. Kilpatrick, C.

Lawrence, et al. Sex difference in amygdala activity during emotionally influenced memory storage. Neurobiology of Learning and Memory, 75 (2001), pp. 1-9

Cahill and van Stegeren, 2003

L. Cahill, A. van Stegeren. Sex-related impairment of memory for emotional events with beta-adrenergic blockade.

Neurobiology of Learning and Memory, 79 (1) (2003), pp. 81-88 Canli et al., 2002

T. Canli, J. Desmond, Z. Zhao, J.D.E. Gabrieli. Sex differences in the neural basis of emotional memories. Proceedings of the National Academy of Sciences of the United States of America, 99 (2002), pp. 10789-10794

Christianson and Mjörndal, 1985

S.-Å. Christianson, T. Mjörndal. Adrenalin, emotional arousal and memory. Scandinavian Journal of Psychology, 26 (1985), pp. 237-248

Christianson et al., 1986

S.-Å. Christianson, L. G. Nilsson, T. Mjörndal, C. Perris, G. Tjelldén. Psychological versus physiological determinants of emotional arousal and its relationship to laboratory induced amnesia. Scandinavian Journal of Psychology, 27 (1986), pp. 300-310

Christianson et al., 1984

Christianson, S.-A., Nilsson, L.-G., Mjörndal, T., Perris, C., \& Tjelldén, G. (1984). Physiological and cognitive determinants of emotional arousal in mediating amnesia. Umeå Psychological Reports, 176

Cohen et al., 1983

Neurobiology of Learning and Memory Vol 84, No. 1 (July 2005): pg. 49-56. DOI. This article is (C) Elsevier and permission has been granted for this version to appear in e-Publications@Marquette. Elsevier does not grant permission for this article to be further copied/distributed or hosted elsewhere without the express permission from Elsevier. 
S. Cohen, T. Kamarck, R. Mermelstein. A global measure of perceived stress. Journal of Health and Social Behavior, 24 (1983), pp. 385-396

Colrain et al., 1992

I.M. Colrain, G.L. Mangan, O.L. Pellett, T.C. Bates. Effects of post-learning smoking on memory consolidation.

Psychopharmacology, 108 (1992), pp. 448-451

Conway et al., 1994

M. Conway, S. Anderson, S. Larsen, F. Steen, C. Donnelly, M.

McDaniel, et al. The formation of flashbulb memories. Memory \& Cognition, 22 (3) (1994), pp. 326-343

Czech et al., 2000

D.A. Czech, K.A. Nielson, K.K. Laubmeier. Chronic administration of propranolol impairs Morris water maze retention in the mouse. Neurobiology of Learning and Memory, 74 (2000), pp. 17-26

de Quervain et al., 2003

D.J. de Quervain, K. Henke, A. Aerni, V. Treyer, J.L. McGaugh, T. Berthold, et al. Glucocorticoid-induced impairment of declarative memory retrieval is associated with reduced blood flow in the medial temporal lobe. European J ournal of Neuroscience, 17 (2003), pp. 1296-1302 de Quervain et al., 2000

D.J. de Quervain, B. Roozendaal, R.M. Nitsch, J.L. McGaugh, C. Hock. Acute cortisone adminstration impairs retrieval of longterm declarative memory in humans. Nature Neuroscience, 3 (2000), pp. 313-314

Deutsch and Deutsch, 1966

J.A. Deutsch, D. Deutsch. Physiological psychology. Dorsey

Press, Homewood, IL (1966)

Easterbrook, 1959

J.A. Easterbrook. The effect of emotion on cue utilization and the organization of behavior. Psychological Review, 66 (1959), pp. 83-201

Ekman et al., 1983

P. Ekman, R.W. Levenson, W.V. Friesen. Autonomic nervous system activity distinguishes among emotions. Science, 221 (4616) (1983), pp. 1208-1210

Gold and McCarty, 1981

Neurobiology of Learning and Memory Vol 84, No. 1 (July 2005): pg. 49-56. DOI. This article is (C) Elsevier and permission has been granted for this version to appear in e-Publications@Marquette. Elsevier does not grant permission for this article to be further copied/distributed or hosted elsewhere without the express permission from Elsevier. 
P.E. Gold, R. McCarty. Plasma catecholamines: Changes after footshock and seizure-producing frontal cortex stimulation. Behavioral and Neural Biology, 31 (1981), pp. 247-260 Gold and McGaugh, 1975

P.E. Gold, J.L. McGaugh. A single-trace, two-process view of memory storage processes. D. Deutsch, J.A. Deutsch (Eds.), Short-term memory, Academic Press, New York (1975), pp. 355- 378

Gold and van Buskirk, 1975

P.E. Gold, R. van Buskirk. Facilitation of time-dependent memory processes with posttrial epinephrine injections. Behavioral Biology, 13 (1975), pp. 145-153

Gomez et al., 2005

P. Gomez, P. Zimmermann, S. Guttormsen-Schar. Respiratory responses associated with affective processing of film stimuli.

Biological Psychology, 68 (3) (2005), pp. 223-235

Guy and Cahill, 1999

S.C. Guy, L. Cahill. The role of overt rehearsal in enhanced conscious memory for emotional events. Consciousness and Cognition, 8 (1999), pp. 114-122

Kemp and Nathan, 2004

A.H. Kemp, P.J. Nathan. Acute augmentation of serotonin suppresses cardiovascular responses to emotional valence. International J ournal of Neuropsychopharmacology, 7 (1) (2004), pp. 65-70

Kuhlmann et al., 2005

S. Kuhlmann, C. Kirschbaum, O.T. Wolf. Effects of oral cortisol treatment in healthy young women on memory retrieval of negative and neutral words. Neurobiology of Learning and Memory, 83 (2005), pp. 158-162

Lacey and Lacey, 1970

J.I. Lacey, B.C. Lacey. Some autonomic-central nervous system interrelationships. P. Black (Ed.), Physiological correlates of emotion, Academic Press, New York (1970), pp. 205-227

Libkuman et al., 1999

T.M. Libkuman, P. Nichols-Whitehead, J. Griffith, R. Thomas. Source of arousal and memory for detail. Memory \& Cognition, 27 (1) (1999), pp. 166-190

Livingston, 1967

Neurobiology of Learning and Memory Vol 84, No. 1 (July 2005): pg. 49-56. DOI. This article is @ Elsevier and permission has been granted for this version to appear in e-Publications@Marquette. Elsevier does not grant permission for this article to be further copied/distributed or hosted elsewhere without the express permission from Elsevier. 
R.B. Livingston. Reinforcement. G. Quarton, T. Melnechuk, F. Schmitt (Eds.), The neurosciences: a study program, Rockefeller Press, New York (1967), pp. 514-576

Maheu et al., 2004

F.S. Maheu, R. Joober, S. Beaulieu, S.J. Lupien. Differential effects of adrenergic and corticosteroid hormonal systems on human short- and long-term declarative memory for emotionally arousing material. Behavioral Neuroscience, 118 (2) (2004), pp. 420-428

Manning et al., 1992

C.A. Manning, M. Parsons, P.E. Gold. Anterograde and retrograde enhancement of 24-h memory by glucose in elderly humans. Behavioral and Neural Biology, 58 (1992), pp. 125-130 McGaugh, 1990

J.L. McGaugh. Significance and remembrance: The role of neuromodulatory systems. Psychological Science, 1 (1990), pp. $15-25$

McGaugh, 2000

J.L. McGaugh. Memory-a century of consolidation. Science, 287

(14) (2000), pp. 248-251 (January)

Müller and Pilzecker, 1900

G.E. Müller, A. Pilzecker. Experimentelle beitrage zur lehre vom gedachtnis [Experimental contributions in learning and memory]. Zeitschrift für Psychologie Erganzungsband, 1 (1900), pp. 1-288

Nielson and Bryant, 2005

Nielson, K. A., Bryant, T. (2005). The effects of non-contingent extrinsic and intrinsic rewards on memory consolidation. Neurobiology of Learning and Memory.

Nielson et al., 1999

K.A. Nielson, D.A. Czech, K.K. Laubmeier. Chronic administration of propranolol impairs inhibitory avoidance retention in the mouse. Neurobiology of Learning and Memory, 71 (1999), pp. 248-257

Nielson and J ensen, 1994

K.A. Nielson, R.A. Jensen. Beta-adrenergic receptor antagonist antihypertensive medications impair arousal-induced modulation of working memory in elderly humans. Behavioral and Neural Biology, 62 (1994), pp. 190-200 
Nielson et al., 1996

K.A. Nielson, R.C. Radtke, R.A. Jensen. Arousal-induced modulation of memory storage processes in humans.

Neurobiology of Learning and Memory, 66 (1996), pp. 133-142

Okuda et al., 2004

S. Okuda, B. Roozendaal, J.L. McGaugh. Glucocorticoid effects on object recognition memory require training-associated emotional arousal. Proceedings of the National Academy of the Sciences United States of America, 101 (3) (2004), pp. 853-858 Paivio et al., 1968

A. Paivio, J.C. Yuille, S.A. Madigan. Concreteness, imagery, and meaningfulness values for 925 nouns. Journal of Experimental Psychology, 76 (Suppl.) (1968), pp. 1-25

Powless et al., 2003

Powless, M., Nielson, K. A., Gunderson, P., Bournas, V., Galloway, J., \& Czech, D. A. (2003, November). Human memory modulation is effective using comedy and when delayed up to 30 minutes after learning. Paper presented at the Society for Neuroscience, New Orleans, LA. Abstract Viewer and Itinerary Planner, Program No. 129.10

Quevedo et al., 2003

J. Quevedo, M.K. Sant' Anna, M. Madruga, I. Lovato, F. de-Paris, F. Kapczinski, et al. Differential effects of emotional arousal in short- and long-term memory in healthy adults. Neurobiology of Learning and Memory, 79 (2) (2003), pp. 132-135

Revelle and Loftus, 1992

W. Revelle, D.A. Loftus. The implications of arousal effects for the study of affect and memory. S. Christianson (Ed.), The handbook of emotion and memory, Lawrence Erlbaum, Hillsdale (1992), pp. 113-150

Shaw et al., 1995

G.A. Shaw, D.A. Bekerian, J.A. McCubbin. Effects of videotaped violence on hypermnesia for imaginally encoded concrete and abstract words. Perceptual and Motor Skills, 80 (1995), pp. 467477

Southwick et al., 2002

S.M. Southwick, M. Davis, B. Horner, L. Cahill, C.A.R. Morgan, P.E. Gold, et al. Relationship of enhanced norephinphrine activity during memory consolidation to enhanced long-term

Neurobiology of Learning and Memory Vol 84, No. 1 (July 2005): pg. 49-56. DOI. This article is @ Elsevier and permission has been granted for this version to appear in e-Publications@Marquette. Elsevier does not grant permission for this article to be further copied/distributed or hosted elsewhere without the express permission from Elsevier. 
memory in humans. American J ournal of Psychiatry, 159

(2002), pp. 1420-1422

Stone and Nielson, 2001

L.A. Stone, K.A. Nielson. Physiological response to arousal and impaired emotional expression in alexithymia. Psychotherapy and Psychosomatics, 70 (2001), pp. 92-102

Torras-Garcia et al., 1997

M. Torras-Garcia, I. Portell-Cortes, D. Costa-Miserachs, I. Morgado-Bernal. Long-term memory modulation by posttraining epinephrine in rats differential effects depending on the basic learning capacity. Behavioral Neuroscience, 111 (1997), pp. 301-308

van Stegeren et al., 1998

A.H. van Stegeren, W. Everaerd, L. Cahill, J.L. McGaugh, L.J.G. Gooren. Memory for emotional events: Differential effects of centrally versus peripherally acting beta-blocking agents.

Psychopharmacology, 138 (1998), pp. 305-310

Varner and Ellis, 1998

L.J. Varner, H.C. Ellis. Cognitive activity and physiological arousal: Processes that mediate mood-congruent memory. Memory \& Cognition, 26 (5) (1998), pp. 939-950

Walker, 1958

E.L. Walker. Action decrement and its relation to learning.

Psychological Review, 65 (1958), pp. 129-142

Wechsler, 1981

D. Wechsler. WAIS revised manual. The Psychological

Corporation, New York (1981)

Witvliet and Vrana, 1995

C.V. Witvliet, S.R. Vrana. Psychophysiological responses as indices of affective dimensions. Psychophysiology, 32 (5) (1995), pp. 436-443

Wolf et al., 2001

O.T. Wolf, A. Convit, P.F. McHugh, E. Kandil, E.L. Thorn, S. De Santi, et al. Cortisol differentially affects memory in young and elderly men. Behavioral Neuroscience, 105 (2001), pp. 10021011

Yerkes and Dodson, 1908

Neurobiology of Learning and Memory Vol 84, No. 1 (July 2005): pg. 49-56. DOI. This article is (C) Elsevier and permission has been granted for this version to appear in e-Publications@Marquette. Elsevier does not grant permission for this article to be further copied/distributed or hosted elsewhere without the express permission from Elsevier. 
NOT THE PUBLISHED VERSION; this is the author's final, peer-reviewed manuscript. The published version may be accessed by following the link in the citation at the bottom of the page.
R. Yerkes, J. Dodson. The relation of strength of stimulus to rapidity of habit-formation. Journal of Comparative Neurology and Psychology, 18 (1908), pp. 459-482 